\title{
Adverbs of change, aspect, and underspecification*
}

\author{
Todor Koev \\ University of Dïsseldorf
}

\begin{abstract}
Adverbs of change like quickly or slowly are known to give rise to a number of interpretations. For example, Selena ran quickly says that the rate of running is high while Selena quickly noticed the plane implies that the distance between the event of noticing the plane and some previous event is short. Existing accounts (e.g. Cresswell 1978; Rawlins 2013) take rate readings as primary but struggle to derive additional interpretations. By contrast, I argue that adverbs of change measure the temporal distance between two salient events (or event parts) that are compositionally or contextually available. The main claim of the paper is that adverbs of change have a single if underspecified semantics and that the different interpretations arise through interaction with aspectual and discourse structure.
\end{abstract}

Keywords: adverbial modification, change, aspect, underspecification, context, event semantics

\section{Introduction: The class of adverbs of change}

Change is a fundamental part of the human experience and not surprisingly it is amply represented in natural language. Languages can express change directly, i.e. by means of verbal predicates with certain aspectual properties, or indirectly, e.g. by building narratives or specifying how discourse interaction evolves. This paper investigates the semantics of change through the lens of one understudied class of adverbs, which modify the dimensions of change and offer a unique window into the different ways this notion is grammatically or pragmatically encoded.

Modifiers like quickly, rapidly, fast, swiftly, hastily, slowly, sluggishly, glacially, suddenly, abruptly, instantaneously, immediately, gradually, etc. are typically classified as manner adverbs (Jackendoff 1972; Travis 1988; Parsons 1990; Ernst 2004; Maienborn \& Schäfer 2011; Morzycki 2015). This paper argues that such adverbs display interpretations that barely count as "manner" and should rather be viewed as constituting a class in its own right. Intuitively, such modifiers add some dimension to the change explicitly or implicitly implied by the sentence, e.g. by characterizing

* Many thanks to Hana Filip, Willie Geuder, Zsófia Gyarmathy, Graham Katz, and Peter Sutton. For English judgments, I am indebted to Curt Anderson, Kurt Erbach, and Peter Sutton. 
Adverbs of change

the rate at which the described action evolves, by measuring the time until change occurs, or by specifying the nature of the change as instant or gradual. I thus call such modifiers adverbs of change, somewhat in line with Rawlins' (2013) term "adverbs of time and change". Other names include "adverbs of space and time" or "motion adverbs" (Cresswell 1978), "celerative" adverbs (Cinque 1999), "rate adverbs" (Tenny 2000; Kearns 2007), or “aspect-manner adverbs” (Ernst 2004).

I will not try to do justice to the entire class of adverbs of change but will rather focus on quickly and slowly, and offer a few suggestions about suddenly and gradually. I will propose that modifiers like quickly or slowly measure the temporal distance between a point of change and some salient event, e.g. a previously mentioned event or the event of uttering the sentence. The main claim of the paper is that adverbs of change are not ambiguous, despite their many readings. Rather, they have an underspecified yet uniform semantics that interacts with aspectual and discourse structure.

The paper is structured as follows. Section 2 sorts out the range of possible interpretations for adverbs of change. Section 3 demonstrates that the availability of these interpretations heavily depends on the aspectual properties of the modified predicate. Section 4 critically evaluates previous work, and Section 5 presents the proposal. Section 6 is the conclusion.

\section{The range of available interpretations}

It has been noticed that adverbs of change can give rise to a wide range of interpretations (Cresswell 1978; Travis 1988; Pustejovsky 1991; Shaer 1998; Tenny 2000; Schäfer 2002; Ernst 2004; Thompson 2006; Kearns 2007; Eszes 2009; Rawlins 2013). Although there is little agreement on what these interpretations are, they seem to fall into the following categories (although not necessarily under the same labels): (i) rate, (ii) duration, (iii) narrative, and (iv) deictic/indexical. A rate reading for quickly is illustrated below.

(1) Selena ran quickly.

Rate readings are sometimes called "manner" readings, but it is unclear whether these are two distinct readings or perhaps two labels for one and the same reading. Under a manner reading, (1) characterizes as fast the way Selena moved her body parts; under a rate reading, (1) describes as high the speed at which Selena moved through space. In principle, these two readings are logically independent, and when they are empirically distinguished the "rate" characterization seems more appropriate.

(2) Selena ran on ice. She was moving her legs fast, but due to the little friction she was advancing with a low velocity.

Selena ran ?quickly manner / slowly rate $_{\text {. }}$ 
(3) Selena ran with a jet pack on her back. She was moving her legs slowly, but due to the thrust from the jet pack she was advancing with a high velocity.

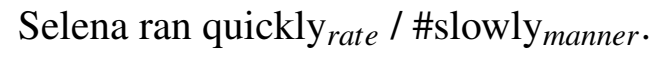

Since only the rate component of the running event in (2)-(3) appears accessible to modification by an adverb of change, I will prefer the "rate" terminology as empirically more adequate.

Duration readings concern the temporal extent of whole events. ${ }^{1}$ For example, (4) describes as short the temporal extent of the complete assignment-writing event, relative to some contextually given standard. Two naturally-occurring examples of duration readings are given in (5)-(6).

(4) Harry completed the assignment quickly.

(5) Recently, emphasis on EST sequencing has waned due to the advent of next generation sequencing techniques that can quickly dissect a transcriptome.

(COCA)

(6) Students were instructed to complete the maze as quickly and as accurately as possible.

(COCA)

Unlike the previous two interpretations, which target single events, narrative readings connect two different events (Shaer 1998). The sentence in (7) carries the implication that the time interval between the event described by the first clause and the one described by the second clause was short. The adverbs of change in the naturalistic examples in (8)-(9) receive a similar interpretation.

(7) The professor walked in and Selena quickly/immediately noticed him.

(8) A low sound came from the direction of the bed, and Addy swiftly moved to the window.

(COCA)

(9) Sam pulled over but immediately realized that whatever he had hit was behind him, in an area where it was too dark for him to see.

(COCA)

Finally, indexical (or deictic) uses of adverbs of change arise with non-assertive speech acts and modify the time between the current speech event and some projected discourse-relevant move, e.g. the act of fulfilling a promise, answering a question, obeying a command, etc.

(10) I promise to quickly write you back.

(11) Quickly, what were the main causes of the Russian Revolution?

(Shaer 1998:13)

1 Such readings are given different names in the literature, including "ratio" (Cresswell 1978), "whole event" (Thompson 2006), or “extent” readings (Rawlins 2013). 
To summarize, adverbs of change can take on different interpretations: rate, duration, narrative, indexical. These interpretations seem to describe properties of change along some concrete or abstract dimension, yet otherwise appear to have little in common. Below I will argue that this puzzling semantic diversity does not arise through lexical ambiguity but rather is due to interaction with aspectual and discourse factors.

\section{Interaction with aspect}

There are systematic and revealing interactions of adverbs of change with aspectual factors. I first introduce the traditional aspectual classes and then discuss how predicates with different aspectual properties restrict available interpretations.

Aspect refers to the "different ways of viewing the internal temporal constituency of a situation" (Comrie 1976:3) by means of verbal predicates which differ across properties like cumulativity, divisibility, quantization, telicity, durativity, homogeneity, dynamicity, agentivity, scalar change, etc. (Vendler 1957; Kenny 1963; Dowty 1979; Bach 1981; 1986; Krifka 1989; 1992; Parsons 1990; Smith 1997; Rothstein 2004; Beavers 2013; a.o.). Ever since Vendler (1957), the denotations of verbal predicates are traditionally divided into four major classes: activities, accomplishments, achievements, and states. ${ }^{2}$ Activity predicates like run, push the cart, sleep, watch $T V$ refer to processes without specified initial or terminal points but have crisp internal structure, consisting of chains of minimal event parts which share certain properties. Accomplishments are described by predicates like run a mile. These are protracted events that end in a culmination. Achievements are instantaneous events and are described by predicates like spot a plane. ${ }^{3}$ Finally, states are expressed by verbs like love or know. Like activities they set no specific boundaries, but unlike them they are homogeneous, i.e. lack minimal parts. ${ }^{4}$

Aspect has a distinct effect on available interpretations for adverbs of change. When modifying activity predicates, such adverbs can only have rate readings. As Thompson (2006) points out, (13) means that John moved fast while pushing the cart and cannot have, say, a durative interpretation, whereby the action of pushing the

2 I will put aside degree achievement predicates like melt, freeze, widen, which express a change of state and can be telic or atelic (Dowty 1979; Hay et al. 1999; Kearns 2007; Kennedy \& Levin 2008; Rothstein 2008) and semelfactive predicates like knock or cough, which refer to achievement-like events but can be iterated (Smith 1997; Rothstein 2008).

3 Ignored here are Bach's (1986) "culminations", i.e. predicates like win the race or reach the summit, which have the properties of Vendler's achievements but include preliminary stages.

4 Alternatively, states may be assumed to have minimal parts that are unstable, underdetermined or vague, and thus difficult to individuate (cf. Chierchia 2010; Rothstein 2010). 
cart took a short period of time. Rawlins (2013) makes similar remarks about (14).

(13) John pushed the cart quickly.

(Thompson 2006:219)

(14) Alfonso ran quickly as compared to Joanna.

(Rawlins 2013:155)

What these authors fail to notice, though, is that not all activity predicates can be modified by adverbs of change. For example, sleep or watch TV cannot.

(15) John slept ?quickly / \#slowly.

(16) Alfonso watched TV \#quickly / \#slowly.

What semantic property is responsible for the contrast in judgment between (13)-(14) and (15)-(16)? One potential explanation is that adverbs of change draw a line between motion vs. non-motion predicates. Cresswell (1978), for example, explicitly states that adverbs of change select for motion predicates (for discussion, see Section 4.1 below). While this is clearly false for non-activity predicates (e.g. complete the assignment does not express physical motion but can be modified by adverbs of change), the processes in (13)-(14) indeed fall into this category. However, processes described by talk or eat are not tied to motion in any obvious way and yet are acceptable with adverbs of change (cf. Lucy ate slowly).

Another idea is that adverbs of change are sensitive to the homogeneity of the modified eventuality. It is generally accepted that states and processes are divisible, in the sense that they can have proper parts that are of the same kind (Bennett \& Partee 1978; Dowty 1979; Bach 1981; Krifka 1989; Champollion \& Krifka 2016), while accomplishments or achievements are not. However, Landman \& Rothstein (2012) claim that activities are "incrementally" homogeneous, as they take time to develop, whereas states are strictly homogeneous and can be true at instants. Taylor (1977) and Dowty (1979) draw a distinction between activities that are heterogeneous (or divisible down to some contextually determined granularity; e.g. walk or talk) vs. activities that are homogeneous (or endlessly divisible; e.g. move or fall). So perhaps adverbs of change can modify heterogeneous activities, as in (13)-(14), but not homogeneous activities, as in (15)-(16). But in fact adverbs of change readily attach to homogeneous predicates like move or fall (cf. The car moved quickly).

I argue that the relevant notion here is change rather than homogeneity. I propose that there are two types of activity predicates, dynamic (e.g. run, move, talk) vs. non-dynamic (e.g. sleep, watch $T V$, rain), and that only those of the former type can be modified by adverbs of change, the intuitive reason being that only the former predicates express change. As far as I know, the distinction between dynamic vs. non-dynamic activities has not been much explored in the aspectual literature. ${ }^{5}$

5 But see Beavers (2013), who assumes that only the former type of predicates are associated with what 
Adverbs of change

Cresswell (1978), Thompson (2006), and Rawlins (2013) claim that, when combined with accomplishment predicates, adverbs of change are ambiguous between rate vs. duration readings. According to Cresswell, the rate reading of (17) says that John walked quickly and his walking was to the station, while the duration reading of (17) says that John's walking was a quick walking to the station.

(17) John walked quickly to the station.

(Cresswell 1978:181)

Rawlins (2013:154) seconds this claim and additionally argues that rate and duration readings are distinguished by different measure phrases inside comparative forms.

(18) Alfonso ran to the park quickly.

a. Alfonso ran to the park 2 miles per hour more quickly than Joanna. (rate)

b. Alfonso ran to the park 2 minutes more quickly than Joanna. (duration)

In (18a), 2 miles per hour modifies the rate of the running while in (18b) 2 minutes tells us something about the temporal extent of the entire event. However, while (18b) is uncontroversial, two out of the three English speakers I consulted do not find (18a) acceptable. Notice also that when the extent reading is explicitly denied, the rate reading is not readily available.

(19) ? Alfonso ran to the park quickly, but it took him a long time to get there.

(20) \# The plane fell to the ground quickly, but it took a long time before it crashed.

Given the hesitance of English speakers with data as in (18a), (19) and (20), I will tentatively assume that adverbs of change lack rate readings with accomplishment predicates. $^{6}$

Accomplishment sentences also give rise to narrative interpretations.

(21) The tiger walked into the room. Kazuko quickly moved to the window.

When combined with achievement predicates, adverbs of change can only give rise to narrative readings. The sentence below is repeated from (7) above.

(22) The professor walked in and Selena quickly/immediately noticed him.

Finally, stative predicates are generally unacceptable with adverbs of change (Thomason \& Stalnaker 1973; Katz 2003; Rawlins 2013). If at all acceptable, (23) can only mean that the person in question started to like her job shortly after some implied event, i.e. we get a coerced inchoative reading. Other, more natural cases of state coercion are cited in (24)-(25).

he calls a "scale of change". Maienborn (2007:ft.4) calls predicates like sleep or wait stative, due to the fact that they have homogeneous reference. However, such predicates display the distributional properties of activity predicates, e.g. occur in the progressive in episodic present tense uses.

6 It is possible that rate readings are available with some but not other accomplishment predicates. 
? She quickly liked her job.

He suddenly/quickly realized his mistake.

John sat in his chair going over the day's perplexing events again in his mind. Suddenly, he was asleep.

(Dowty 1986:38)

Deictic interpretations of adverbs of change are in principle possible with predicates of all aspectual classes, although some predicates may be more natural that others in particular speech acts. What matters here is the properties of the action implied by the speech act performed, not necessarily the aspect of the depicted predicate. For example, (11) above contains a stative predicate but is fully natural with quickly because it can target the anticipated event of answering the question.

A summary of the empirical findings, excluding cases of aspectual coercion, is given below. (Unavailable interpretations are left unmarked.)

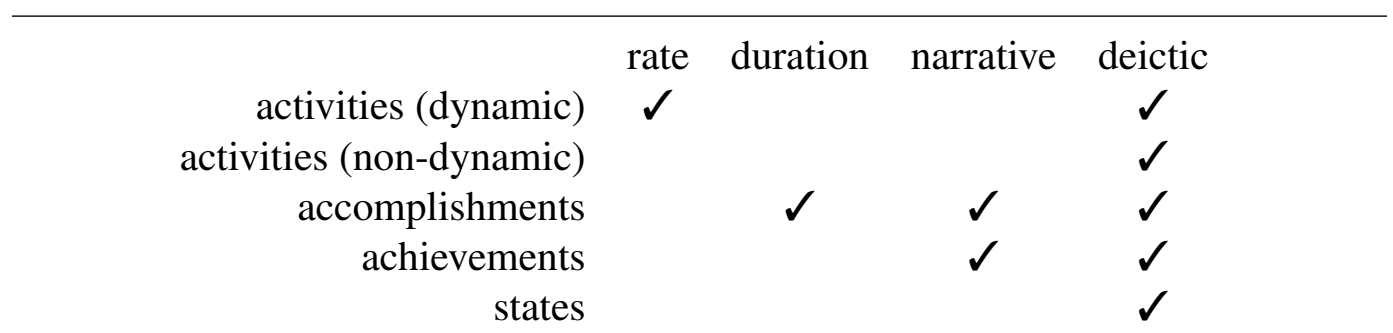

Table 1 Readings for adverbs of change with different aspectual classes

In this section I have shown that the range of available interpretations for adverbs of change is heavily restricted by the aspectual properties of the modified predicate. The task then is to make sense of the puzzling multitude of interpretations by combining insights from aspectual and discourse structure. After critically evaluating two previous proposals in Section 4, I will present my own account in Section 5.

\section{Previous work on adverbs of change}

Cresswell (1978) was the first to propose a semantic analysis for adverbs of change. This paper develops a formal account of rate and duration readings for quickly, and also recognizes the existence of narrative readings. Subsequent research has tried to attribute available readings to structural or lexical ambiguities (Travis 1988; Pustejovski 1991; Tenny 2000; Schäfer 2002; Ernst 2004; Thompson 2006; Kearns 2007; Eszes 2009). Rawlins (2013) offers the most elaborate discussion to date and systematically investigates the interaction between adverbs of change and aspectual class. In this section, I will critically evaluate Cresswell's and Rawlins' accounts, as these authors offer the most theoretical depth. 
Adverbs of change

\subsection{Cresswell (1978)}

Cresswell's (1978) main claim is that adverbs of change modify motion predicates and compare the ratio between the distance traveled and the time passed to some average value. Cresswell takes rate readings as basic (although he calls these "manner" readings) and assumes that adverbs of change modify not the duration of the described event as a whole but rather the duration of its minimal parts. He writes:

"The manner sense of quickly [when applied to walk] involves, I claim, not taking the distance of the whole walk and comparing it with the time taken, but rather taking the minimal subintervals of that interval which are intervals of walking and saying that the ratio of distance to time in most of them is above average for walkings occurring during intervals of that length." (Cresswell 1978:180)

Cresswell fleshes out this idea as follows. If a sentence $\phi$ is true at an interval $t$, then $t^{*} \subseteq t$ is a minimal subinterval of $t$ relative to $\phi$ iff $\phi$ is true at $t^{*}$ and there is no proper subinterval of $t^{*}$ at which $\phi$ is true. Also, for an individual $a$ and a time interval $t$, let $\pi(a, t)$ stand for the path of $a$ during $t, \delta(\pi(a, t))$ stand for the spatial distance between the beginning and the endpoint of $\pi(a, t)$, and $\delta(t)$ stand for the temporal duration of $t$. The rule for quickly then requires that the modified sentence be true at the time of evaluation and that for most minimal subintervals the distance/time ratio be above average. ${ }^{7}$

(26) If $P$ is a motion property, $a$ is an individual, and $t$ is a time interval, then $\llbracket$ quickly $\rrbracket(P)(a)$ is true at $t$ iff

- $P(a)$ is true at $t$, and

- for most minimal subintervals $t^{*}$ of $t$ relative to $P(a)$ :

$$
\frac{\delta\left(\pi\left(a, t^{*}\right)\right)}{\delta\left(t^{*}\right)}>\operatorname{avg}\left\{\frac{\delta\left(\pi\left(x, t^{\prime}\right)\right)}{\delta\left(t^{\prime}\right)} \mid \delta\left(t^{\prime}\right)=\delta\left(t^{*}\right) \wedge P(x) \text { is true at } t^{\prime}\right\}
$$

This interpretation rule predicts that Jim walked quickly entails that Jim walked and that for most minimal subintervals relative to Jim walked it holds that Jim walked a longer distance than the average of some relevant comparison class of walkings during intervals of the same length. Notice that this rule only requires that most (not all) minimal subintervals of walking have the specified property: Jim's walk would count as quick even if occasionally he slows down. ${ }^{8}$ While Cresswell's paper

7 In order to ensure uniformity throughout this paper, I slightly adapt Cresswell's original notation.

8 Alternatively, one could assume universal quantification over minimal subintervals and attribute the few exceptions to the specified condition to vagueness. 
exclusively focuses on quickly, a semantic rule for slowly would presumably look as in (26) but will have the greater-than sign substituted with a less-than sign.

One issue with Cresswell's semantic rule for quickly is that the comparison class is based on minimal subintervals relative to the described action, and this may lead to problems. Assume that nothing smaller than a step counts as walking and imagine that Jim, an Olympic champion in race walking, just performed the quickest walk ever, in the sense that most of his steps were faster than any steps previously performed. We would certainly want to say that Jim walked quickly. However, since the comparison is based on the intervals of Jim's steps, which are too short to comprise any other person's steps, the comparison class will consist of Jim's distance/time ratios alone. This means that at most one half of Jim's ratios will be greater than his own average and Jim cannot be said to have walked quickly, contrary to intuition. ${ }^{9}$ What seems to be needed here is a comparison between the duration of Jim's steps and the duration of walking steps in general. In other words, we can dispense with ratios or paths traveled and directly compare times. An alternative semantic rule for quickly that does not inherit the above problem is given below.

If $P$ is a property of individuals, $a$ is an individual, and $t$ is a time interval, then $\llbracket$ quickly $\rrbracket(P)(a)$ is true at $t$ iff

- $P(a)$ is true at $t$, and

- for most minimal subintervals $t^{*}$ of $t$ relative to $P(a)$ and any individual $x$ : the duration of $t^{*}$ is less than the average duration of minimal subintervals $t^{\prime}$ of $t$ relative to $P(x)$.

This modified definition has some additional empirical advantages. It also accounts for uses of adverbs of change that are not based on motion in space.

(28) John ran quickly on the treadmill.

(29) The water heated slowly.

(Rawlins 2013:161)

(30) Alfonso solved the problem quickly.

(Rawlins 2013:161)

The main merit of Cresswell's analysis is that it can capture duration readings by using a uniform meaning for adverbs of change and making certain natural assumptions about the semantics of telic predicates. Cresswell proposes to derive the duration reading of John walked quickly to the station by letting quickly modify the entire verb phrase and assuming the following semantic rule for directional to-phrases. ${ }^{10}$

9 If one tries to somehow exclude Jim's walking from constructing the comparison class, we will produce the empty set and the average value cannot be computed.

10 The sentence John walked quickly to the station is assumed to also have a rate reading (or a "manner" 
Adverbs of change

(31) If $a, b$ are individuals and $P$ is a motion property: $\llbracket$ to $\rrbracket(b)(P)(a)$ is true at $t$ iff

- $P(a)$ is true at $t$,

- there is no interval $t^{\prime}$ such that $t \subset t^{\prime}$ and $P(a)$ is true at $t^{\prime}$, and

- $t$ has a last moment $m$ such that $\pi(a, m)$ and $\pi(b, m)$ overlap.

According to (31), John walked to the station is true at $t$ iff John walked is true at $t$, there is no proper superinterval of $t$ at which John walked is true, and John's location and the location of the station overlap at the last moment of $t$. The sentence John walked quickly to the station then says that most minimal intervals of John's walking to the station are shorter than an average walking to the station. Since the semantics for to requires that any interval of walking to the station be maximal, this amounts to saying that the single interval of John's walking to the station is shorter than some relevant average. This is just the duration reading for quickly.

Cresswell acknowledges the existence of narrative uses for adverbs of change. He contends that what is being modified in such uses is the interval during which the expressed proposition becomes true. On this view, Someone quickly entered implies that Someone entered became true fast. This idea makes narrative uses somewhat similar to duration uses, but it is unclear how it can be fleshed out or derived compositionally.

In summary, Cresswell's (1978) proposal captures rate and duration readings, and also recognizes the existence of narrative readings for adverbs of change. The main disadvantage, though, is that his account does not really engage with aspect and also does not mention indexical readings. ${ }^{11}$ A more comprehensive analysis needs to take into consideration all readings and explain their aspect-sensitivity.

\subsection{Rawlins (2013)}

According to Rawlins (2013), adverbs of change denote functions that distribute over event structure and measure out temporal duration. Thus, Alphonso ran quickly will be true just when Alphonso ran and the duration of the atomic running events is shorter than some contextually supplied standard. Although framed in a neoDavidsonian event semantics (e.g. Parsons 1990), the core idea behind this analysis is similar to Cresswell's (1978):

reading, in Cresswell's terminology) and attributed to a parsing whereby quickly modifies the verb alone. However, in view of the discussion in Section 2, I disregard rate readings with accomplishment predicates as dubious.

11 To be fair, Cresswell does say that rate and duration readings arise with predicates of a "different logical kind" (p.184). What he presumably has in mind is the distinction between activity and accomplishment predicates, respectively. 
"The intuition for e.g. "runs quickly" is that we look at the minimal parts of a running event that are still runnings [...] and check whether they are all shorter than typical comparable minimal runnings [...]. For a running event, these atoms naturally correspond to something like individual steps or motions [...].” (Rawlins 2013:170-171)

Rawlins proposes that adverbs of change have the same meaning throughout, and derives different readings by interaction with event structure, including aspect and narrative discourse. The main advantage of this account is that it engages and explains, at least to some extent, the dependence of available interpretations on lexical and discourse structure. ${ }^{12}$

Rawlins assumes that the events in the denotation of verbal predicates are mereologically structured into join semilattices (Bach 1986; Krifka 1989; 1992; Link 1998; Zucchi \& White 2001). Adverbs of change quantify over the relevant atoms of such domains and compare their duration to some contextually provided standard. This is formally achieved by means of the following definitions. Given an event $e$ and an event property $P$, lat $(e, P)$ is the maximal set of parts of $e$ that fall under $P$ and form a join semilattice relative to the part-of relation $\sqsubseteq$. atoms $(e, P)$ is the set of atomic parts of $e$ that fall under $P$, where $\sqsubset$ is the proper part-of relation. The set of homogeneous $P$-atoms of $e, \operatorname{hatoms}(e, P)$, is then defined as the set of atomic parts in lat $(e, P)$. This is the set that adverbs of change distribute over. ${ }^{13}$

$$
\begin{aligned}
& \operatorname{lat}(e, P)=\max \left\{E \mid \forall e^{\prime} \in E\left[e^{\prime} \sqsubseteq e \wedge P\left(e^{\prime}\right)\right] \wedge\langle E, \sqsubseteq\rangle \text { is a join semilattice }\right\} \\
& \operatorname{atoms}(e, P)=\left\{e^{\prime} \sqsubseteq e \mid P\left(e^{\prime}\right) \wedge \neg \exists e^{\prime \prime}\left[e^{\prime \prime} \sqsubset e^{\prime} \wedge P\left(e^{\prime \prime}\right)\right]\right\} \\
& \operatorname{hatoms}(e, P)=\operatorname{lat}(e, P) \cap \operatorname{atoms}(e, P)
\end{aligned}
$$

Quickly expresses a property of events that distributes over the set produced by hatoms and requires that the duration of its elements be shorter than some contextually given standard. A simplified interpretation rule is given below, where $\tau$ is the temporal trace function (a function from events to temporal intervals), $|\cdot|$ is the temporal extent function (a function from intervals to non-negative numbers), $\sigma$ is a standard function, $C_{H}$ is some contextually supplied property of events, and $C_{C}$ is a comparison class of relevant events.

$$
\begin{aligned}
& \llbracket \text { quickly } \rrbracket=\lambda e \cdot \forall e^{\prime} \in \operatorname{hatoms}\left(e, C_{H}\right)\left[\left|\tau\left(e^{\prime}\right)\right|<\sigma\left(C_{C}\right)\right] \\
& \text { provided that hatoms }\left(e, C_{H}\right) \text { is non-empty }
\end{aligned}
$$

12 This account also makes predictions about the distribution of measure phrases in sentences with adverbs of change.

13 I take the freedom of significantly simplifying these definitions. Importantly, I ignore Rawlins' notion of "immediate accessibility", intended to capture the alleged rate/duration ambiguity of adverbs of change with accomplishment predicates. 
Adverbs from the opposite part of the scale (e.g. slowly) will reverse the direction of the comparison and require that each homogeneous atom be above standard length.

This semantics correctly predicts several cases of interaction with aspect. First, Rawlins assumes that adverbs of change are sortally restricted to events proper, and thus cannot modify stative predicates. Achievement predicates would be ruled out as well if we assume that the events in their denotations, which are felt to be instantaneous, have no duration. In that case it would be impossible to satisfy the requirement that the duration of the events modified by adverbs of change be strictly bigger or strictly smaller than a standard of zero. ${ }^{14}$

Activity predicates give rise to rate interpretations because adverbs of change distribute over the atoms of the lattice structure, provided that $C_{H}$ is equated with the denotation of the activity predicate. Recalling (15)-(16) though, this account does not explain why only some activity predicates can be modified by adverbs of change. If both dynamic and non-dynamic activities are underlined by atomic parts, there is no principled reason why adverbs of change cannot measure those parts.

Although not explicitly discussed in Rawlins (2013), his account can derive the duration readings for adverbs of change with accomplishment predicates. If we let $C_{H}$ be the denotation of an accomplishment predicate, the distribution would be over complete events and we would measure events in their entirety. ${ }^{15}$ This account follows the spirit of Cresswell (1978) but captures the rate vs. duration readings for adverbs of change by the context sensitivity of $C_{H}$ rather than by recourse to a structural ambiguity.

In order to explain narrative readings, Rawlins borrows from the literature on temporal progression the idea that events are temporally ordered by their relationship to "reference times" (Reichenbach 1947; Kamp \& Rohrer 1983; Partee 1984; Dowty 1986; Hinrichs 1986; Lascarides \& Asher 1993; Klein 1994) but modifies it in various ways. Specifically, Rawlins makes the following three assumptions. First, narrative discourse is chunked not into reference times but rather into narrative events, which have the aspectual properties of accomplishments. Second, described events are temporally contained and right-aligned with the narrative event. Third, sequenced narrative events are closely aligned to each other. Rawlins' main claim is that narrative readings are just duration readings in disguise; they arise when adverbs of change modify narrative events. The first assumption about narrative discourse is then needed because adverbs of change are taken to modify events rather than times. The second and the third assumptions ensure that the duration of the current narrative event determines the distance between the current event and some

14 If, to the contrary, achievements are assumed to have a positive if very short duration, then there would be no reason why such events cannot be measured by adverbs of change.

15 I once again ignore alleged rate readings with accomplishment predicates. These can be derived if the set of homogeneous atoms is computed relative to the verb alone rather than the entire verb phrase. 
previously described event.

One serious wrinkle with this story is that it does not predict any specific interaction between narrative readings and aspect. If narrative events were real, an adverb of change should be able to pick it out independently of the aspectual properties of the predicate inside the clause. This incorrectly predicts that (in narrative discourses) adverbs of change are fully natural with all sorts of predicates, including stative predicates, yet in reality they are not (cf. He sent her flowers and \#she quickly loved him). I conclude that this proposal makes no reasonable predictions about narrative readings of adverbs of change, at least not without significant modifications.

Overall, Rawlins' account explains a great deal about the interaction of adverbs of change and aspect. At the same time, it leaves a lot to be desired. It does not draw a distinction between dynamic and non-dynamic activity predicates, it ignores the aspectual properties of verbal predicates in narrative readings for adverbs of change, and it does not engage with deictic readings. In addition, stative predicates are ruled out by stipulation, which may not seem explanatory. My own proposal, developed in the following section, tries to address all those issues.

\section{Proposal}

Existing accounts take rate readings of adverbs of change as primary and try to work their way from there toward explaining additional interpretations. The key idea is that these modifiers measure the spatial and/or temporal parameters of minimal instances of the described action and compare these parameters to some appropriate standard. Under this view, adverbs of change measure single events. By contrast, I propose that adverbs of change modify the temporal distance between two instantaneous events (or event parts), called an anchor and a target, where the former temporally precedes the latter. The target event is compositionally available and is intrinsically linked to the aspectual properties of the sentence. It is invariably what I call a culmination, or an "event which the speaker views as punctual or instantaneous, and as accompanied by a transition to a new state of the world" (Moens \& Steedman 1988:16). ${ }^{16}$ In turn, the anchor event is underspecified and drawn from a set of contextually salient events.

As already mentioned in Section 3, verbal predicates are typically divided into four major classes: activities, accomplishments, achievements, and states. I have also argued that adverbs of change are sensitive to the distinction between dynamic vs. non-dynamic activity predicates (e.g. ride a bike vs. watch $T V$, respectively), in that they can only modify the former but not the latter type. We thus arrive at the following aspectual typology, where graphical representations are to be read as

16 Since such transitions can occur inside composite events, this notion of a culmination is not a label for a specific eventuality type, in contrast to Bach's (1986) “culmination” achievements. 
Adverbs of change

evolving in time from left to right. I use a dashed line to mark processes, a straight line to mark states, and black dots to mark what I have called culminations, i.e. instantaneous events that signal change.

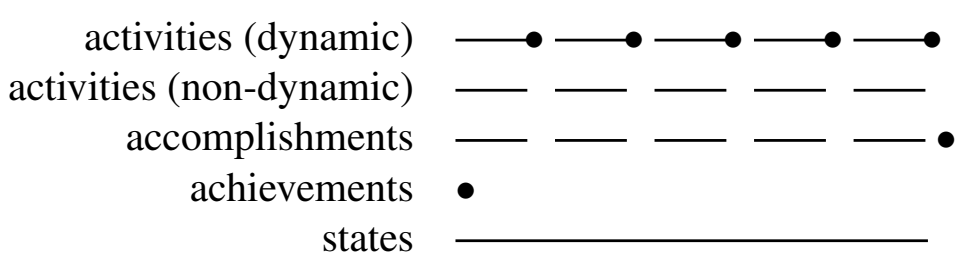

Figure 1 Graphical representations of major eventuality types

States illustrate the simplest case, as they are homogeneous and hold over time; they do not express change and include no culminations. Unlike states, activities are segmented into larger chunks, as they take time to develop. Activities also allow for gaps, i.e. intervals at which the process is "put on hold" (Landman \& Rothstein 2012). I assume that the difference between dynamic vs. non-dynamic activities is that the former but not the latter type effectuate change and thus their minimal segments culminate. Accomplishments are composite events which consist of processes and end in a culmination. ${ }^{17}$ Finally, achievements are instantaneous events and consist of a single culmination.

The just outlined aspectual typology predicts quite well the range of available interpretations for adverbs of change, if it is assumed that such modifiers target culmination points. First, stative and non-dynamic activity predicates are not acceptable with adverbs of change because they provide no suitable targets. Achievement predicates give rise to narrative interpretations because the target is the achievement event itself and the underspecified event (the anchor) is some temporally anterior event. When modifying accomplishment predicates, adverbs of change target the culmination point while the anchor is resolved to some salient previous event. It seems plausible to assume that two such events are the initial part of the described event (which derives a duration reading) or some previously mentioned event (which derives a narrative reading). In order to explain rate readings, we let adverbs of change distribute over the minimal parts of the dynamic process. This idea is borrowed from Cresswell (1978) and Rawlins (2013), and what is measured here is the distance between the culmination of each minimal part and its beginning. Finally,

17 What is ignored here is that processes inside accomplishments can be dynamic (e.g. run the race) or non-dynamic (e.g. sleep for two hours). This distinction is less relevant here because of the assumption, made in Section 3, that adverbs of change with accomplishment predicates lack rate readings. The semantics below will be set up in such a way that the underlying process in accomplishments cannot be accessed. 
deictic readings are derived by relating the projected action described or implied by the utterance and the current speech event. Since such projected actions can be conceptualized as instantaneous, they are good targets for adverbs of change.

I now demonstrate how this analysis can be made formally precise. First, let us define the culmination of a $P$-eventuality $e$ to be the final segment of $e$ if that segment expresses change relative to $P$ (36). The final segment of $e$ is one that is not temporally followed by another segment of $e$ and that is contained in any other final segment of $e$ (37). ${ }^{18}$ A segment $e^{\prime}$ expresses change relative to a property $P$ and eventuality $e$ iff there is some relevant property $Q$ that $e^{\prime}$ has but that no prior segment of $e$ has (38). Here I leave the nature of $Q$ unspecified, although it seems clear that $Q$ is intrinsically linked to the type of change expressed by $P .{ }^{19}$

$$
\begin{aligned}
& \operatorname{cul}(e, P)= \imath e^{\prime}\left[P(e) \wedge e^{\prime} \sqsubseteq_{f} e \wedge \operatorname{CHA}\left(e^{\prime}, e, P\right)\right] \\
& e^{\prime} \sqsubseteq e \wedge \\
& e^{\prime} \sqsubseteq f e \text { iff } \neg \exists e^{\prime \prime} \sqsubseteq e\left[\tau\left(e^{\prime}\right) \prec \tau\left(e^{\prime \prime}\right)\right] \wedge \\
& \forall e^{\prime \prime \prime} \sqsubseteq e\left[\neg \exists e^{\prime \prime \prime \prime} \sqsubseteq e\left[\tau\left(e^{\prime \prime \prime}\right) \prec \tau\left(e^{\prime \prime \prime \prime}\right)\right] \rightarrow e^{\prime} \sqsubseteq e^{\prime \prime \prime}\right] \\
& \operatorname{CHA}\left(e^{\prime}, e, P\right) \text { iff } \exists Q \sim P\left[Q\left(e^{\prime}\right) \wedge \forall e^{\prime \prime} \sqsubseteq e\left[\tau\left(e^{\prime \prime}\right) \prec \tau\left(e^{\prime}\right) \rightarrow \neg Q\left(e^{\prime \prime}\right)\right]\right]
\end{aligned}
$$

As under previous accounts, I will assume that adverbs of change distribute over eventuality structure. In order to provide a quantificational domain for adverbs of change, we need to single out the relevant atoms with a given property. This can be achieved by means of Krifka's $(1989 ; 1992) P$-atom property. ${ }^{20}$

$$
\begin{aligned}
& \operatorname{atom}(e, P)=\left\{e^{\prime} \sqsubseteq e \mid P(e) \wedge \operatorname{ATOM}\left(e^{\prime}, P\right)\right\} \\
& \operatorname{ATOM}\left(e^{\prime}, P\right) \text { iff } P\left(e^{\prime}\right) \wedge \neg \exists e^{\prime \prime} \sqsubset e^{\prime}\left[P\left(e^{\prime \prime}\right)\right]
\end{aligned}
$$

A semantic rule for quickly is given below. Here $A_{c}$ is a set of contextually salient events from which anchors are chosen, $\delta\left(e_{1}, e_{2}\right)$ stands for the temporal distance between $e_{1}$ and $e_{2}$ (only defined if $e_{1}$ temporally precedes $e_{2}$ ), $n<_{\varepsilon_{c}} m$ states that $n$ is at least $\varepsilon_{c}$-smaller than $m$ (i.e., $n+\varepsilon_{c} \leq m$ ), and $\sigma_{c}$ is some contextually supplied standard distance.

$$
\llbracket \text { quickly } \rrbracket^{c}=\lambda P \lambda e . P(e) \wedge \forall e^{\prime} \in \operatorname{atom}(e, P) \exists a \in A_{c}\left[\delta\left(a, \operatorname{cul}\left(e^{\prime}, P\right)\right)<_{\varepsilon_{c}} \sigma_{c}\right]
$$

This rule is in line with previous accounts but it differs in several important respects. The first difference is that adverbs of change target the culminations of the relevant

18 Notice that the existence of a unique final segment presupposes an atomic domain of eventualities.

19 In these definitions, $\sqsubseteq$ is the part-of relation, $\tau$ is the temporal trace function, $\prec$ is a strict precedence order over times, and $\sim$ is a relevance relation.

20 It may seem unrealistic that the size of such atoms is fixed by the model once and for all, as different contexts may require different levels of granularity. We could thus relativize (39)-(40) to contexts $c$ and require that only events of a minimum duration of $i_{c}$ are considered. 
atoms, which is crucial for barring quickly from modifying states or non-dynamic activities. Another difference is that what is measured is the temporal distance between two disjoint events (or event parts), where the anchor event $a$ is left unspecified. This feature is best seen at work in narrative or deictic interpretations. Finally, the said distance needs to be not just smaller but significantly smaller than the provided standard; the significance level is modulated by the parameter $\varepsilon_{c}$. Indeed, if the duration of Jack's steps is just above or below some standard duration for walking, his activity would hardly count as a quick or slow walking.

The rule in (41) derives the attested readings for quickly with predicates with different aspectual properties as follows. First, notice that the culmination function will be undefined on stative or non-dynamic activity predicates, the reason being that the relevant atoms inside the denotations of such predicates (mereological atoms in the former case, bigger chunks in the latter case) contain no culminations. This explains why quickly cannot modify predicates with these aspectual properties.

Dynamic activities differ from non-dynamic ones in that their atoms end in culmination points. Rate readings with such eventuality types then can be explained by assuming that quickly measures the temporal distance between the beginning and the culmination of each atomic part.

Since accomplishment or achievement predicates refer to quantized events, the set of relevant atoms will contain complete events only, i.e. no two events in the denotation of such predicates will stand in a proper part-of relation to one another. ${ }^{21}$ With accomplishment predicates, quickly will target the culmination of each event and could be anchored to its beginning (in duration readings) or some previous event (in narrative readings). With achievement predicates, quickly will target entire events and will be anchored to some previous event, thus producing narrative interpretations. In all those cases distributivity plays no role and the meaning for quickly in $c$ boils down to $\lambda P \lambda e . P(e) \wedge \exists a \in A_{c}\left[\delta(a, \operatorname{cul}(e, P))<\varepsilon_{c} \sigma_{c}\right]$.

As for the deictic readings of quickly, I will focus on examples as in (42) because these represent the most extreme case, in the sense that the event of the hearer answering the question that is targeted by the adverb of change is left implicit. I assume that (42) has the Logical Form in (42a), where SAY is a silent speech act operator and $Q$ is a polar question operator that turns propositions into sets of propositions. The meaning in (42b) expresses a relation between propositions of the form It is raining or It is not raining and events of the hearer of $c$ (marked as $\mathbf{h} \mathbf{r}_{c}$ ) uttering one of those propositions shortly after some event $a$. If we let $a$ be the event of uttering (42) itself, we get a deictic interpretation: the hearer is being urged to answer the question quickly.

21 For example, if John built three houses and noticed four planes, the atom function will produce three non-overlapping events for John built a house and four non-overlapping events for John noticed a plane. 
Quickly, is it raining?

a. [SAY quickly] $[Q$ raining]

$$
\text { b. } \lambda p \lambda e .\left[\begin{array}{l}
\operatorname{say}\left(e, \mathbf{h r}_{c}, p\right) \wedge \\
\exists a \in A_{c}\left[\boldsymbol{\delta}\left(a, \mathbf{c u l}\left(e, \lambda e^{\prime} . \operatorname{say}\left(e^{\prime}, \mathbf{h r}_{c}, p\right)\right)<\varepsilon_{c} \sigma_{c}\right] \wedge\right. \\
p=\lambda w . \operatorname{rain}(w) \vee p=\lambda w . \neg \operatorname{rain}(w)]
\end{array}\right]
$$

The meaning in (42b) can be compositionally derived by assuming the propositional meaning for raining in (43), a meaning for $Q$ as in (44), and a meaning for $S A Y$ as in (45).

$$
\begin{aligned}
& \llbracket \text { raining } \rrbracket^{c}=\lambda w \text {.rain }(w) \\
& \llbracket Q \rrbracket^{c}=\lambda q \lambda p \cdot p=\lambda w \cdot q(w) \vee p=\lambda w . \neg q(w) \\
& \llbracket S A Y \rrbracket^{c}=\lambda R \lambda Q \lambda p \lambda e .\left[R\left(\lambda e . \operatorname{say}\left(e, \mathbf{h} \mathbf{r}_{c}, p\right)\right)(e) \wedge Q(p)\right]
\end{aligned}
$$

In the last part of this section, I briefly address the typology of adverbs of change. We have seen that quickly lends itself to four different readings: rate, duration, narrative, and deictic. Since quickly and slowly appear to be antonyms, a first thought is that slowly has a similar semantics but one where the direction of the comparison is reserved, i.e. we require that the distance between the anchor and the target events be larger than the standard. However, Pustejovski (1991) and Ernst (2004) notice that slowly has a more restricted semantic distribution. ${ }^{22}$ Indeed, slowly seems to lack narrative or deictic uses. For example, sentences that describe achievements are generally restricted to narrative readings and are natural with quickly but not with slowly.

The professor walked in. Selena quickly / ?slowly noticed him.

Another piece of the evidence involves co-occurrences of two adverbs of change. If both quickly and slowly felicitously appear in the same clause, they have to take on two different readings in order to avoid a contradiction. The data below shows that it is natural to read quickly narratively and interpret slowly as a rate modifier, but not vice versa.

a. Mark left the house. Quickly, he started running slowly.

b. Mark left the house. ?Slowly, he started running quickly.

In addition, slowly, unlike quickly, lacks deictic readings.

22 I do not fully agree with the specific claims made or the plausibility of the provided examples in the cited works, and thus I do not discuss these here. However, I do believe that the general direction of the observations made is correct. 
Adverbs of change

Quickly / \#Slowly, what is the capital of Uganda?

We can explain the missing narrative and deictic readings by assuming that slowly modifies a single event. This can be formally modeled by requiring that the anchor is invariably the initial portion of the target event. The semantic rule below would produce a rate or duration reading only, depending on the aspectual properties of the modified predicate.

$$
\llbracket \text { slowly } \rrbracket^{c}=\lambda P \lambda e . P(e) \wedge \forall e^{\prime} \in \operatorname{atom}(e, P)\left[\delta\left(\operatorname{ini}\left(e^{\prime}\right), \operatorname{cul}\left(e^{\prime}, P\right)\right)>_{\varepsilon_{c}} \sigma_{c}\right]
$$

While modifiers like quickly or slowly tell us something about the duration of the change described or implied by the sentence, other adverbs from the same class may impose different restrictions on the type of change expressed. For example, gradually implies stepwise change (cf. Piñón 2000) that seems oriented toward a specific goal. This modifier thus selects for predicates that are both durative and telic, including accomplishments (cf. She gradually built a career in advertising), and excluding (instantaneous) achievements as these are non-durative (cf. ?He gradually noticed the plane) or processes as these are atelic (cf. \#John gradually ran). Notice that gradually can also occur with degree achievement predicates (cf. The road gradually widened), which is unsurprising, as such predicates are known to have telic uses (cf. The soup cooled in an hour; see Hay et al. 1999; Kearns 2007; Kennedy \& Levin 2008; Rothstein 2008). While gradually entails moderate change, on the opposite side of the spectrum are modifiers like suddenly or abruptly, which imply sudden change. These modifiers thus select for achievements (cf. She suddenly realized she was lost) but exclude durative events (cf. ?He abruptly wrote a sentence on the blackboard). I leave the precise semantic analysis of these modifiers to future research.

\section{Conclusion}

This paper was devoted to explaining the different interpretations of a class of modifiers which I called adverbs of change. I argued that adverbs of change have a single meaning and that the different interpretations arise through interaction with aspectual or discourse structure. I focused on quickly and slowly, which were argued to measure the temporal distance between two events that are salient and are compositionally or contextually accessible in the given linguistic environment. While the proposed account was able to explain all major readings for adverbs of change, it did so by factoring in underspecification. Since it was left open how anchor events are resolved, the proposed account can lead to overgeneration. What is then still missing is a fully worked out theory of what parts of the event structure are or are not relevant to the semantics of change. 


\section{References}

Bach, Emmon. 1981. On time, tense, and aspect: An essay in English metaphysics. In Peter Cole (ed.), Radical Pragmatics, 63-81. New York: Academic Press.

Bach, Emmon. 1986. The algebra of events. Linguistics and Philosophy 9: 5-16.

Beavers, John. 2013. Aspectual classes and scales of change. Linguistics 51(4): 681-706.

Bennett, Michael \& Barbara H. Partee. 1978. Toward the Logic of Tense and Aspect in English. Bloomington: Indiana University Linguistics Club.

Champollion, Lucas \& Manfred Krifka. 2016. Mereology. In Paul Dekker \& Maria Aloni (eds.), Cambridge Handbook of Semantics, 369-388. Cambridge: Cambridge University Press.

Chierchia, Gennaro. 2010. Mass nouns, vagueness and semantic variation. Synthese 174: 99-149.

Comrie, Bernard. 1976. Aspect. Cambridge: Cambridge University Press.

Cinque, Guglielmo. 1999. Adverbs and Functional Heads: A Cross-linguistic Perspective. New York: Oxford University Press.

Cresswell, Max J. 1978. Adverbs of space and time. In F. Guenthner \& S. Schmidt (eds.). Formal Semantics and Pragmatics for Natural Languages, 171-199. Reidel.

Dowty, David. 1979. Word Meaning and Montague Grammar. Dordrecht/Boston: Reidel.

Dowty, David. 1986. The effects of aspectual class on the temporal structure of discourse: semantics or pragmatics? Linguistics and Philosophy 9: 37-61.

Ernst, Thomas. 2004. The Syntax of Adjuncts. Cambridge/New York: Cambridge University Press.

Eszes, Boldizsár. 2009. Aspect and adverb interpretation - the case of quickly. In Katalin Kiss (ed.). Adverbs and Adverbial Adjuncts at the Interface, 269-294. De Gruyter.

Hay, Jennifer, Christopher Kennedy, \& Beth Levin. 1999. Scalar structure underlies telicity in "degree achievements". In Tanya Matthews \& Devon Strolovitch (eds.), Semantics And Linguistic Theory 9: 127-144. Ithaca, NY: Cornell University.

Hinrichs, Erhard. 1986. Temporal anaphora in discourses of English. Linguistics and Philosophy 9: 63-82.

Jackendoff, Ray. 1972. Semantic Interpretation in Generative Grammar. Cambridge/London: MIT Press.

Kamp, Hans \& Christian Rohrer. 1983. Tense in text. In Bäuerle, R., C. Schwartze, \& A. von Stechow A. (eds.), Meaning, Use and Interpretation in Language, 250-269. Berlin: de Gruyter.

Katz, Graham. 2003. Event arguments, adverb selection, and the Stative Adverb Gap. 
Adverbs of change

In E. Lang, C. Maienborn \& C. Fabricius-Hansen (eds.), Modifying Adjuncts (Interface Explorations 4), 455-474. Mouton de Gruyter.

Kearns, Kate. 2007. Telic senses of deadjectival verbs. Lingua 117: 26-66.

Kennedy, Christopher \& Beth Levin. 2008. Measure of change: The adjectival core of degree achievements. In McNally, Louise \& Christopher Kennedy (eds.), Adjectives and Adverbs: Syntax, Semantics, Discourse, 156-182. Oxford: Oxford University Press.

Kenny, Anthony. 1963. Action, Emotion, and Will. London: Routledge \& Kegan Paul.

Klein, Wolfgang. 1994. Time in Language. London/New York: Routledge.

Krifka, Manfred. 1989. Nominal reference, temporal constitution and quantification in event semantics. In Renate Bartsch, Johan van Benthem \& Peter von Emde Boas (eds.), Semantics and Contextual Expression, 75-115. Dordrecht: Foris Publications.

Krifka, Manfred. 1992. Thematic relations as links between nominal reference and temporal constitution. In Ivan A. Sag \& Anna Szabolcsi (eds.), Lexical Matters, 28-53. Stanford University.

Landman, Fred \& Susan Rothstein. 2012. The felicity of aspectual for-phrases. Part I: Homogeneity \& Part II: Incremental homogeneity. Language and Linguistics Compass 6/2: 85-96 and 97-112.

Lascarides, Alex \& Nicholas Asher. 1993. Temporal interpretation, discourse relations and common sense entailment. Linguistics and Philosophy 16: 437-493.

Link, Godehard. 1998. Algebraic Semantics in Language and Philosophy. Stanford: CSU Publications.

Maienborn, Claudia. 2007. On Davidsonian and Kimian states. In I. Comorovski \& K. von Heusinger (eds.), Existence: Semantics and Syntax, 107-130. Springer.

Maienborn, Claudia \& Schäfer, Martin. 2011. Adverbs and adverbials. In Klaus von Heusinger, Claudia Maienborn, \& Paul Portner (eds.), Semantics: An International Handbook of Natural Language Meaning, vol. 2, 1390-1420. Berlin/Boston: De Gruyter.

Moens, Marc \& Mark Steedman. 1988. Temporal ontology and temporal reference. Computational Linguistics 14(2): 15-28.

Morzycki, Marcin. 2015. Modification. Cambridge: Cambridge University Press. Parsons, Terence. 1990. Events in the Semantics of English. Cambridge: MIT Press. Partee, Barbara. 1984. Nominal and temporal anaphora. Linguistics and Philosophy 7: 243-286.

Piñón, Christopher. 2000. Happening gradually. Berkeley Linguistic Society 26: 445-456. University of California, Berkeley: Berkeley, CA.

Pustejovski, James. 1991. The syntax of event structure. Cognition 41: 47-81.

Rawlins, Kyle. 2013. On adverbs of space and time. In B. Arsenijevic et al. (eds.), 
Studies in the Composition and Decomposition of Event Predicates, 153-193. Dordrecht: Springer.

Reichenbach, Hans. 1947. Elements of Symbolic Logic. New York: The Macmilian Company.

Rothstein, Susan. 2004. Structuring Events. Maiden: Blackwell Publishing.

Rothstein, Susan. 2008. Two puzzles for a theory of lexical aspect: Semelfactives and degree achievements. In J. Dölling, T. Heyde-Zybatow, \& M. Schaefer (eds.), Event Structures in Linguistic Form and Interpretation, 175-198. Berlin: Mouton De Gruyter.

Rothstein, Susan. 2010. Counting and the mass/count distinction. Journal of Semantics 27: 343-397.

Schäfer, Martin. 2002. Pure manner adverbs revisited. Sinn und Bedeutung 6: 311323. Osnabrück: Publications of the Institute of Cognitive Science.

Shaer, Benjamin. 1998. Adverbials, functional structure, and restrictiveness. In Pius Tamanji \& Kiyomi Kusumoto (eds.), North East Linguistic Society 28: 391-407. Amherst: GLSA.

Smith, Carlota. 1997. The Parameter of Aspect. Dordrecht/Boston/London: Kluwer, Second edition.

Taylor, Barry. 1977. Tense and continuity. Linguistics and Philosophy 1: 199-220.

Tenny, Carol L. 2000. Core events and adverbial modification. In Carol Tenny \& James Pustejovsky (eds.), Events as Grammatical Objects, 285-334. Stanford: CSLI Publications.

Thomason, Richmond H. \& Robert C. Stalnaker. 1973. A semantic theory of adverbs. Linguistic Inquiry 4: 195-220.

Thompson, Ellen. 2006. The structure of bounded events. Linguistic Inquiry 37: 211-228.

Travis, Lisa. 1988. The syntax of adverbs. McGill Working Papers in Linguistics: Special Issue on Comparative Germanic Syntax. McGill University.

Vendler, Zeno. 1957. Verbs and times. The Philosophical Review 66(2): 143-160.

Zucchi, Sandro \& Michael White. 2001. Twigs, sequences and the temporal constitution of predicates. Linguistics and Philosophy 24: 223-270.

Todor Koev

Universitätsstrasse 1

Department of Linguistics

Heinrich Heine University, Düsseldorf

40225 Düsseldorf, Germany

tkoev@scarletmail.rutgers.edu 